\title{
Preparation and Characterization of Indium Doped Tin Oxide (ITO) via a Solvothermal Method
}

\author{
Anh Khuong Quoc Nguyen and Van Thi Thanh Ho \\ Department of Geology and Mineral, Hochiminh City University of Natural Resources and Environment, Hochiminh 700000, \\ Vietnam
}

\begin{abstract}
Tin-doped Indium Oxide (ITO) has been successfully prepared via solvothermal method with a mixture of Indium(III) acetylacetonate and Tin(IV) bis(acetylacetonate)dichloride in oleyamine solvent under the condition of the different reaction time from $12 \mathrm{~h}$ to $48 \mathrm{~h}$ for the first time. The morphology, phase composition and particle size of the ITO powder were characterized by TEM and XRD. Two significant properties required for ITO samples to become noncarbon support for Pt in PEMFCs including specific surface area and electrical conductivity were studied.
\end{abstract}

Key words: ITO, indium doped tin oxide, solvothermal, conductivity, nanoparticles.

\section{Introduction}

Nowadays, solvothermal synthesis has been widely applied to prepare conventional and advanced nanomaterial especially metal oxides. This method is defined that the synthesis of inorganic materials in organic media at elevated temperatures under autogenous pressure of the organics using a close vessel called an autoclave [1]. Most metal oxide synthesized via solvothermal route perform well-defined morphologies and quite narrow particle size distribution [2, 3]. In addition, this technique facilitates the formation of metal oxides nanoparticles at low temperature and the product obtains the high crystalline without post-calcination [4-6].

Recently, much attention has been paid to Polymer Electrolyte Membrane Fuel Cells (PEMFCs) mainly due to their potential applications in the portable electronics and automobile industries [7]. The issues concerning durability of PEMFCs are one of the important problems that hinder fuel cell commercialization. Carbon has been known as a common catalyst support material for Platinium (Pt) at

Corresponding author: Van Thi Thanh Ho, associate professor, main research field: fuel cells. cathode side of PEMFC. However, during the operation of PEMFCs, there is a decrease in Electrochemical Surface Area (ECSA) of the catalyst result of $\mathrm{Pt}$ dissolution, sintering, as well as agglomeration. This was caused by the severe corrosion of carbon support in the cathode following the reaction: $\mathrm{C}+2 \mathrm{H}_{2} \mathrm{O} \rightarrow \mathrm{CO}_{2}+4 \mathrm{H}^{+}+4 \mathrm{e}^{-}(0.207 \mathrm{~V}$ vs NHE, $25{ }^{\circ} \mathrm{C}$ ) [8-10]. Accordingly, carbon support needs to be substituted to improve the lifetime of electrocatalyst in PEMFCs operation.

Recent intensive research efforts have led to more abundant noncarbon supports for PEMFCs including metal oxides [11-15]. Tin Doped Indium Oxide (ITO) is one of the potential metal oxide supports for $\mathrm{Pt}$ at cathode side of PEMFC [16]. ITO thin film came into widespread commercial use in the areas of liquid crystal displays, optoelectronic devices, heat reflecting mirrors, and sensors on account of its remarkable characteristics such as high electrical conductivity and high transparency under visible light [17-23]. However, the ITO powder was used as support catalyst for Pt in PEMFCs that is quite novel subject.

In the present study, the authors present a solvothermal route to prepare ITO nanoparticles involving the reaction of indium acetylacetonate and 
tin bis(acetylacetonate)dichloride in oleyamine. The specific surface and the conductivity of ITO nanoparticles are also examined to show the competence required for Pt support in PEMFCs.

\section{Material and Methods}

\subsection{Materials}

All precursors and solvents are commercially available and used without further purification. Indium(III) acetylacetonate (In(acac)3, 99.99\%), oleyamine $(70 \%)$ were purchased from Acros-Belgium. Tin(IV) bis(acetylacetonate)dichloride (98\%) were purchased from Sigma-Aldrich. Ethanol (99.7\%) was obtained from Xilong-China.

\subsection{Preparation}

The starting materials, $0.2699 \mathrm{~g}$ of $\operatorname{In}(\mathrm{acac})_{3}$ and $0.026 \mathrm{~g}$ of $\left(\mathrm{Sn}(\mathrm{acac})_{2} \mathrm{Cl}_{2}\right)$ were mixed with $4 \mathrm{~mL}$ of oleyamine under constantly magnetic stirring at 500 rpm for 1 hour. The reaction mixture was transferred into the Teflon lined steel autoclave placed in a lab furnace. Solvothermal reaction was carried out at 220 ${ }^{\circ} \mathrm{C}$ with the reaction time varying from 12 hours to 48 hours. After cooling down to room temperature, the resultant precipitate was centrifuged, washed with ethanol for several times and dried at $80^{\circ} \mathrm{C}$ for $12 \mathrm{~h}$ in air. All the final ITO powders were blue.

\subsection{Characterization}

The phases of the nanoparticles were characterized by X-ray Diffractometry (XRD). The particle size and morphology of the particles were examined using Transmission Electron Microscopy (TEM). Surface areas were determined by BET measurement. The conductivity of materials was measured by the four-point probe technique.

\section{Results and Discussion}

The X-ray diffraction patterns of the as-prepared ITO with different reaction time are shown in Fig. 1.
All sharp XRD peaks of the samples can be assigned to the cubic bixbyite phase of indium oxide $\left(\operatorname{In}_{2} \mathrm{O}_{3}\right)$ (JCPDS No. 06-0416) without any trace of crystalline $\mathrm{SnO}_{2}$ as a secondary phase. This result supports the formation of solid solutions rather than the mixture of indium oxide and tin oxide. The narrow XRD peaks of all ITO samples in Fig. 1 are consistent with a large crystal size. All peaks compared to the standard pattern of indium oxide shift to higher $2 \theta$ values because of the smaller radius of $\mathrm{Sn}^{4+}(0.71 \AA)$ in comparison to that of $\operatorname{In}^{3+}(0.8 \AA)$, according to the Bragg Eq. (2) $\mathrm{d} \sin \theta=\lambda$. In addition, ITO nanoparticles are deep blue, which is clearly different from the white color of the nondoped $\mathrm{In}_{2} \mathrm{O}_{3}$ nanoparticles (Fig. 2). This observation can be explained when tin are doped into $\mathrm{In}_{2} \mathrm{O}_{3}$ structure, the oxygen vacancies are presented and contribute to high values of free-electron concentrations. These free electrons have an effect on the UV vis transmission spectra and consequently ITO nanoparticles change to the dark blue color [24-26].

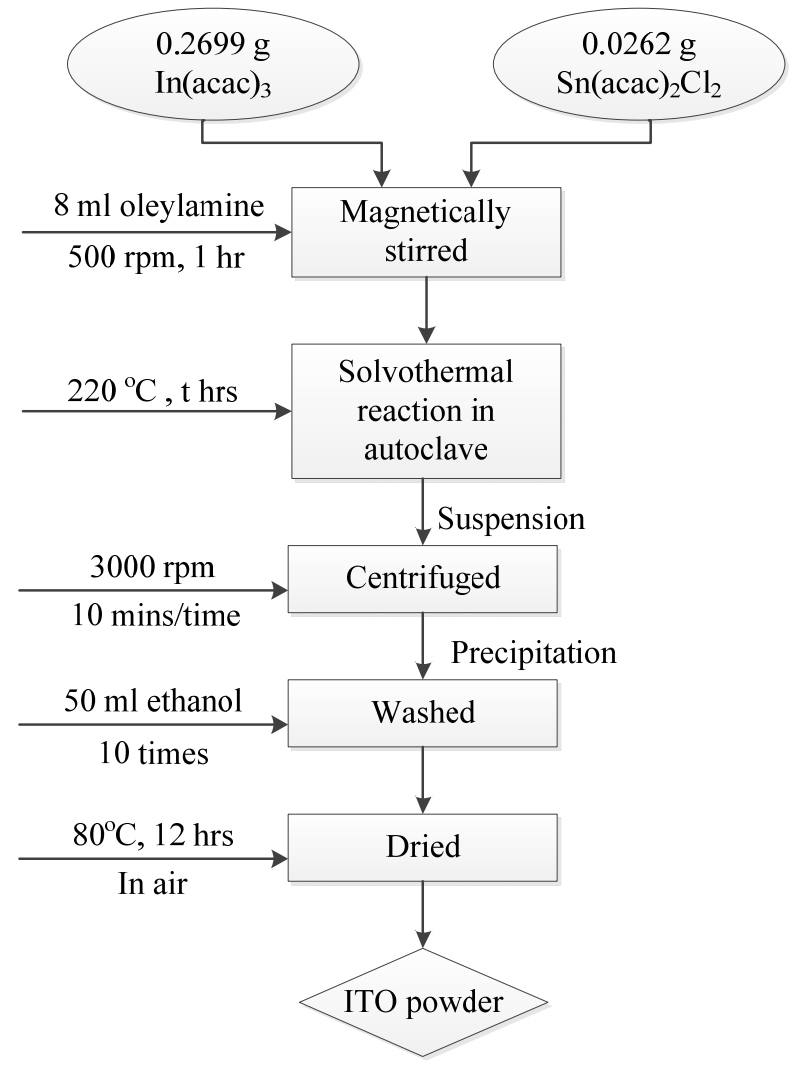

Scheme 1 ITO NPs synthesis process via a solvothermal method. 


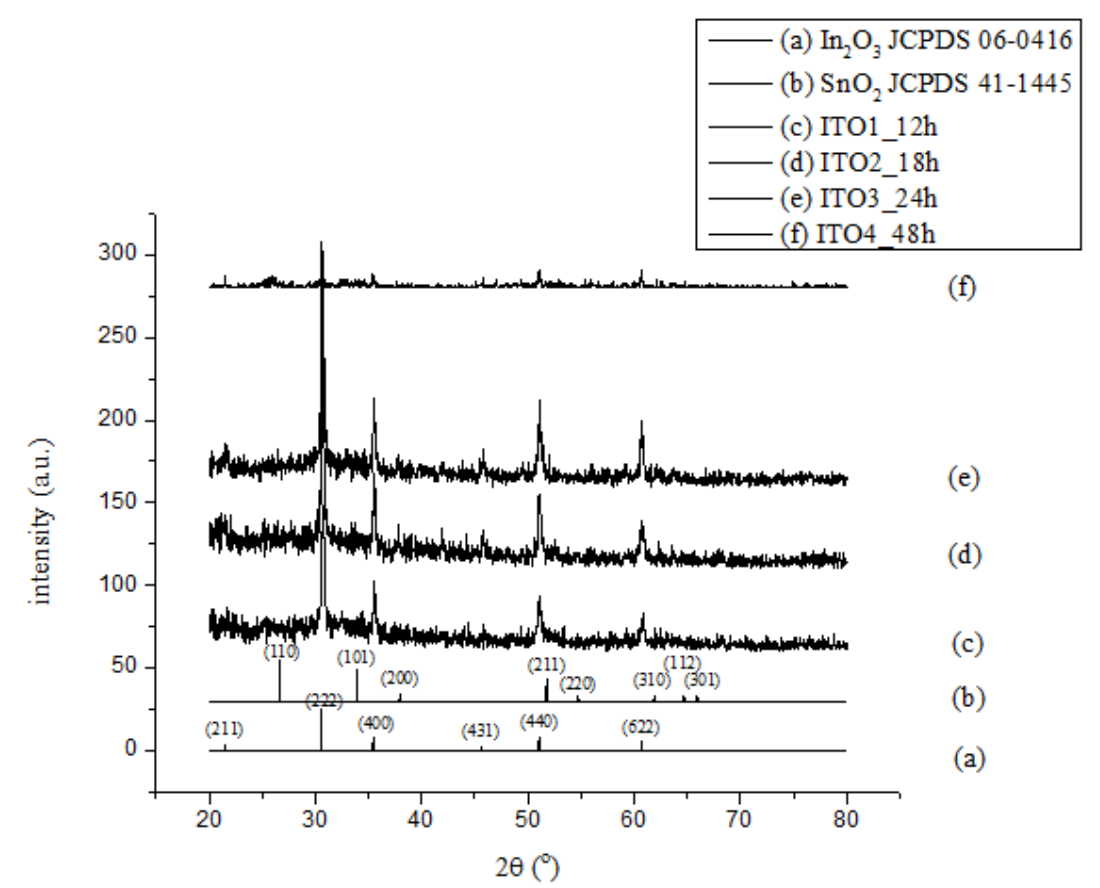

Fig. 1 XRD patterns of Tin-doped Indium Oxide (ITO) NPs with the different reaction time.

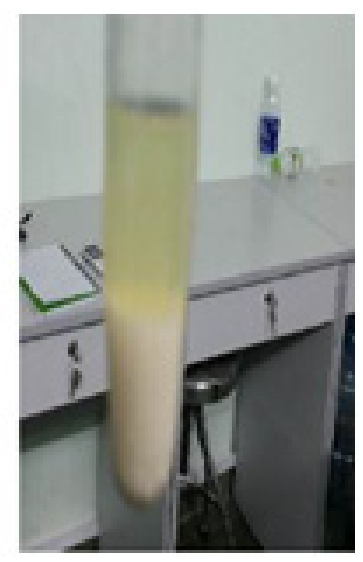

(a)

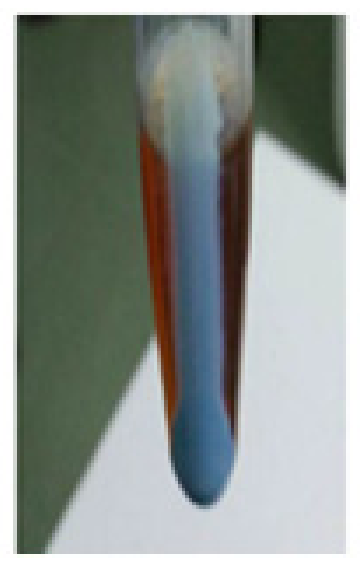

(b)

Fig. 2 The color of $\operatorname{In}_{2} \mathrm{O}_{3}$ sample (a) and ITO sample (b).

Fig. 3 is a series of TEM images showing morphological evolution of the ITO samples. With a short reaction time $(12 \mathrm{~h}-24 \mathrm{~h})$, the crystallite ITO samples give a spherical morphology and the formed spheres are quite uniform (Fig. 3a-3c). The nanospheres over processing times of $12 \mathrm{~h}, 18 \mathrm{~h}$ and $24 \mathrm{~h}$ have a narrow distribution of particle size with an average size of about $50 \mathrm{~nm}$, in accordance with the $\mathrm{XRD}$ results. When the aging time is prolonged to 48 h, ITO4 nanoparticles are completely aggregate which causes the complex morphology formed in Fig. $3 \mathrm{~d}$.

The effect of the reaction time on the surface area (BET) is studied in this work. As can be seen in Fig. 4, with the increase of the processing time, the specific surface area of ITO nanoparticles increases, while the crystal size of powder change insignificantly following the observation from the above TEM imagines. This data could be understood due to the covering of organic ligand on the surface of ITO nanoparticles contributed to the decline in surface area 


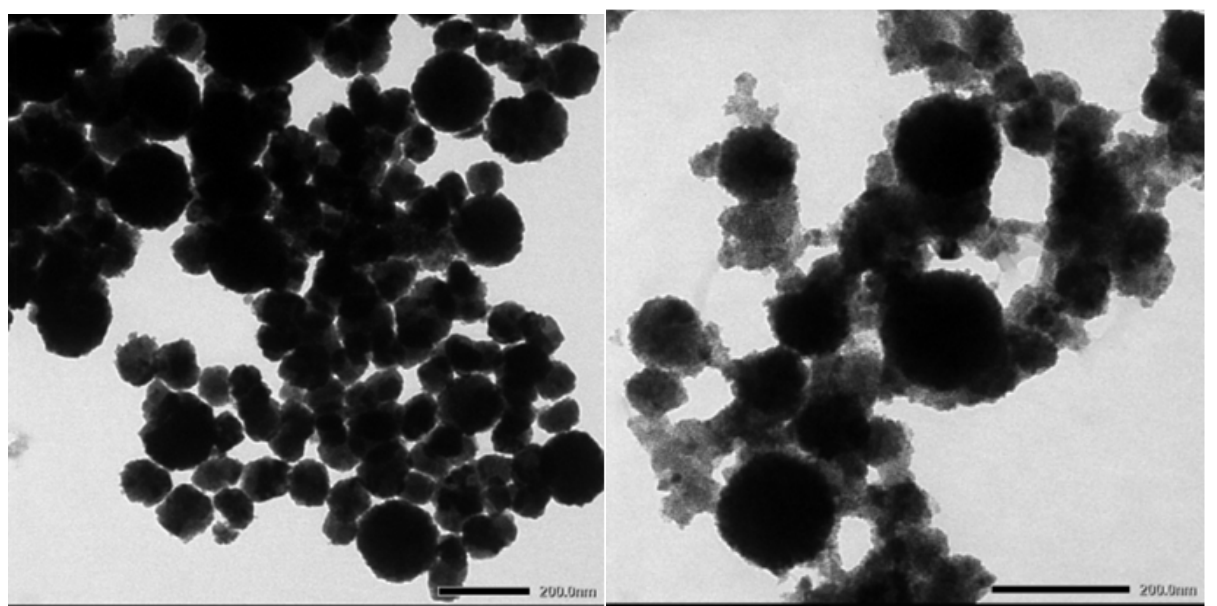

(a)

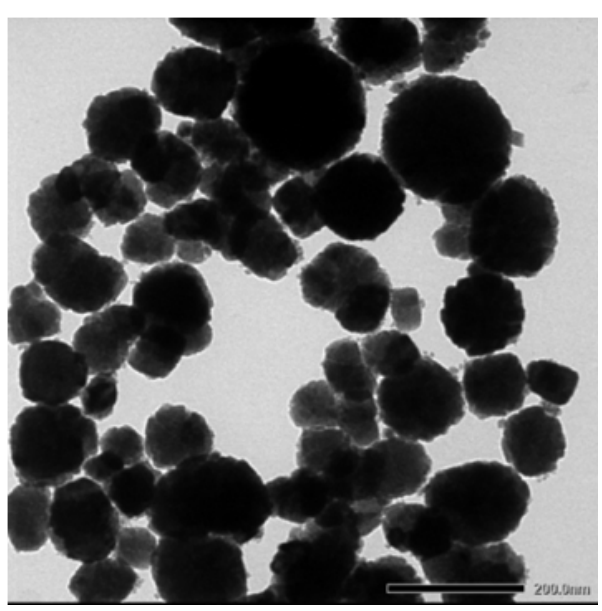

(b)

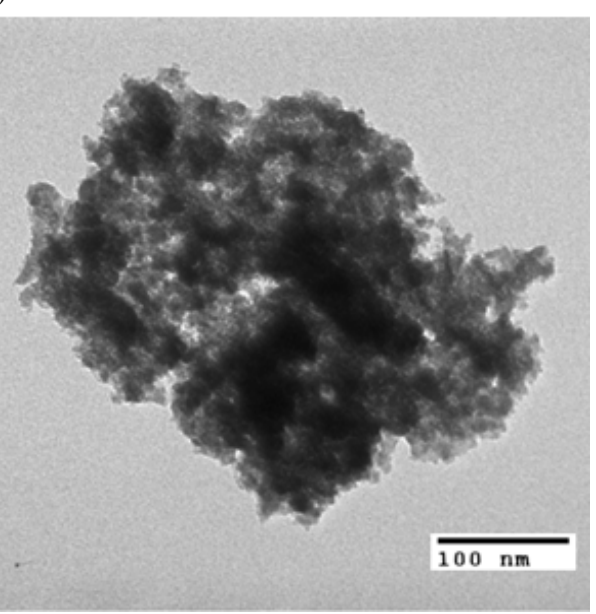

(c)

Fig. 3 TEM micrographs of ITO samples with the different reaction time: 12 h (a); 18 h (b); 24 h (c); 48 h (d).

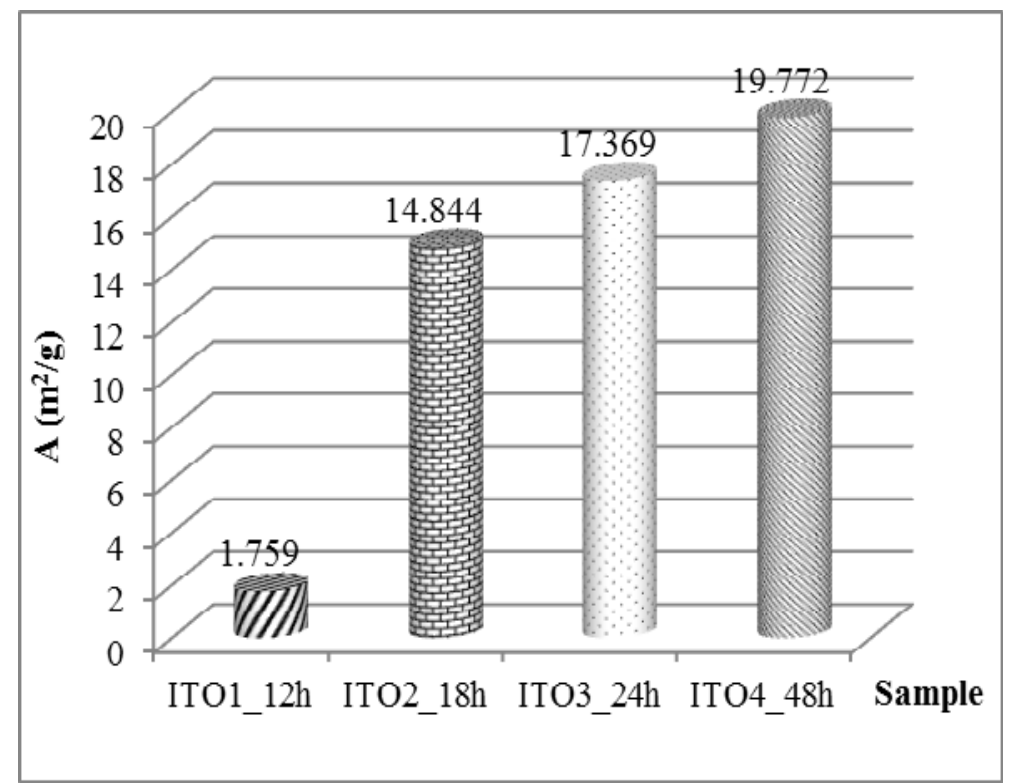

Fig. 4 BET measurement data for ITO samples with the different reaction time. 
of ITO samples. Therefore, when the reaction time is extended, the BET value of ITO samples rise sharply from ITO1 $\left(1.759 \mathrm{~m}^{2} / \mathrm{g}\right)$ to ITO2 $\left(14.844 \mathrm{~m}^{2} / \mathrm{g}\right)$ as a result of organic layer eliminated by continued heat treatment.

\section{Conclusion}

In summary, high crystalinity and high doping level of ITO materials have been successfully prepared by solvothermal reaction of Indium(III) acetylacetonate and Tin(IV) bis(acetylacetonate)dichloride in oleyamine. The authors are currently exploring the ITO4 sample synthesis for $48 \mathrm{~h}$, which is suitable for noncarbon support for Pt in PEMFCs because of its high electrical conductivity. To fully determine the competence of ITO to substitute the carbon support for Pt, this ITO sample will be further investigate by preparing $\mathrm{Pt}$ depositing on the ITO support and comparing with traditional $\mathrm{Pt} / \mathrm{C}$ catalyst.

\section{Acknowledgements}

Authors are grateful for finacial support from The National Foundation for Science and Technology Development given under a special program for Basic Research Projects in Natural Science 2014 (Grants No. 104.03-2014.92) supported for this work.

\section{References}

[1] Demazeau, G. 2000. "High Pressures: Recent Trends in Materials Science." High Pressure Research 18 (1-6): 203-212.

[2] Inoue, M., Nishikawa, T., Otsu, H., Kominami, H., and Inui, T. 1998. "Synthesis of Rare-Earth Gallium Garnets by the Glycothermal Method." Journal of the American Ceramic Society 81 (5): 1173-1183.

[3] Chen, S. J., Chen, X, T., Xue, Z., Li, L. H., and You, X. Z. 2002. "Solvothermal Preparation of $\mathrm{Cu}_{2} \mathrm{O}$ Crystalline Particles." Journal of Crystal Growth 246 (1): 169-175.

[4] Yu, S. H. 2001. "Hydrothermal/Solvothermal Processing of Advanced Ceramic Materials." Journal of the Ceramic Society of Japan 109 (1269): S65-S75.

[5] Stupp, S. I., and Braun, P. V. 1997. "Molecular Manipulation of Microstructures: Biomaterials, Ceramics, and Semiconductors." Science 277 (5330): 1242-1248.
[6] Patzke, G. R., Krumeich, F., and Nesper, R. 2002. "Oxidic Nanotubes and Nanorods-Anisotropic Modules for a Future Nanotechnology." Angewandte Chemie 41 (14): 2446-2461.

[7] Knights, S. D., Colbow, K. M., St-Pierre, J., and Wilkinson, D. P. 2004. "Aging Mechanisms and Lifetime of PEFC and DMFC." Journal of Power Sources 127 (1): 127-134.

[8] Kangasniemi, K. H., Condit, D. A., and Jarvi, T. D. 2004. "Characterization of Vulcan Electrochemically Oxidized under Simulated PEM Fuel Cell Conditions." Journal of The Electrochemical Society 151 (4): E125-E132.

[9] Roen, I. M., Paik, C. H., and Jarvi, T. D. 2004. "Electrocatalytic Corrosion of Carbon Support in PEMFC Cathodes Batteries, Fuel Cells and Energy Conversion." Electrochemical and Solid State Letters 7 (1): A19-A22.

[10] Taniguchi, A., Akita, T., Yasuda, K., and Miyazaki, Y. 2004. "Analysis of Electrocatalyst Degradation in PEMFC Caused by Cell Reversal during Fuel Starvation." Journal of Power Sources 130 (1): 42-49.

[11] Ho, V. T. T., Pillai, K. C., Chou, H. L., Pan, C. J., Rick, J., $\mathrm{Su}$, W. N. et al. 2011. "Robust Non-carbon $\mathrm{Ti}_{0.7} \mathrm{Ru}_{0.3} \mathrm{O}_{2}$ Support with Co-catalytic Functionality for Pt: Enhances Catalytic Activity and Durability for Fuel Cells." Energy \& Environmental Science 4 (10): 4194-4200.

[12] Ho, V. T. T., Pan, C. J., Rick, J., Su, W. N., and Hwang, B. J. 2011. "Nanostructured $\mathrm{Ti}_{0.7} \mathrm{Mo}_{0.3} \mathrm{O}_{2}$ Support Enhances Electron Transfer to Pt: High-Performance Catalyst for Oxygen Reduction Reaction." Journal of the American Chemical Society 133 (10): 11716-11724.

[13] Ho, V. T. T., Nguyen, N. G, Pan, C. J., Cheng, J. H., Rick, J., Su, W. N. et al. 2012. "Advanced Nanoelectrocatalyst for Methanol Oxidation and Oxygen Reduction Reaction, Fabricated as One-Dimensional $\mathrm{Pt}$ Nanowires on Nanostructured Robust $\mathrm{Ti}_{0.7} \mathrm{Ru}_{0.3} \mathrm{O}_{2}$ Support." Nano Energy 1 (5): 687-695.

[14] Nguyen, T. T, Ho, V. T. T, Pan, C. J., Liu, J. Y., Chou, H. L., Rick, J. et al. 2014. "Synthesis of $\mathrm{Ti}_{0.7} \mathrm{Mo}_{0.3} \mathrm{O}_{2}$ Supported-Pt Nanodendrites and Their Catalytic Activity and Stability for Oxygen Reduction Reaction." Applied Catalysis B: Environmental 154-155: 183-189.

[15] Ho, V. T. T, and Nguyen, N. G. 2016. "Advanced Nanostructure $\mathrm{Ti}_{0.7} \mathrm{In}_{0.3} \mathrm{O}_{2}$ Support Enhances Electron Transfer to Pt: Used as High Performance Catalyst for Oxygen Reduction Reaction." Molecular Crystals and Liquid Crystals 635: 1-7.

[16] Nguyen, A. Q. K, Huynh, T. T., Bach, G. L, and Ho, V. T. T. 2016. "Preparation and Characterization of Indium Doped Tin Oxide (ITO) via a Non-aqueous Sol-gel." Molecular Crystals and Liquid Crystals 635: 8-15.

[17] Kim, H., Gilmore, C. M., Pique, A., Horwitz, J. S., 
Mattoussi, H., Murata, H. et al. 1999. "Electrical, Optical, and Structural Properties of Indium-Tin-Oxide Thin Films for Organic Light-Emitting Devices.” Journal of Applied Physics 86 (11): 6451-6461.

[18] Osaz, K., Ye, T., and Aoyagi, Y. 1994. "Deposition of Thin Indium Oxide Film and Its Application to Selective Epitaxy for In Situ Processing.” Thin Solid Films 246 (1): 58-64.

[19] Hambergend, I., and Granquist, C. G. 1986. "Evaporated Sn-doped $\mathrm{In}_{2} \mathrm{O}_{3}$ Films: Basic Optical Properties and Applications to Energy-Efficient Windows." Journal of Applied Physics 60 (11): R123-R160.

[20] Dijaoued, Y., Phong, V. H., Badilescu, S., Ashrit, P. V., Girouard, F. E., and Truong, V. V. 1997. "Sol-gel-Prepared ITO Films for Electrochromic Systems.” Thin Solid Films 293 (1): 108-112.

[21] Mattox, D. M. 1991. "Sol-gel Derived, Air-Baked Indium and Tin Oxide Films." Thin Solid Films 204 (1): 25-32.

[22] Copra, K. L., and Das, S. R. 1983. Thin Film Solar Cell.
New York: Plenum.

[23] Luff, B. J., Wilkinson, J. S., and Perrone, G. 1997. "Indium Tin Oxide Overlayered Waveguides for Sensor Applications." Applied Optics 36 (27): 7066-7072.

[24] Ito, D., Yokoyama, S., Zaikova, T., Masuko, K., and Hutchison, J. E. 2014. "Synthesis of Ligand-Stabilized Metal Oxide Nanocrystals and Epitaxial Core/Shell Nanocrystals via a Lower-Temperature Esterification Process." ACS Nano 8 (1): 64-75.

[25] Jianhua, B., Dina, F. R., Armin, F., Torsten, B., Igor, D., Michael, W. et al. 2006. "Nonaqueous Synthesis of Uniform Indium Tin Oxide Nanocrystals and Their Electrical Conductivity in Dependence of the Tin Oxide Concentration." Chemistry of Materials 18 (12): 2848-2854.

[26] Zhu, X., Jiang, T., Qiu, G., and Huang, B. 2008. "Semiconductivities of Sn-doped $\mathrm{In}_{2} \mathrm{O}_{3}$ Powder Prepared by Co-precipitation through Ion Exchange Method." Materials Chemistry and Physics 112 (2): 342-345. 